\section{DIREITO}

V.8・N.2 2020 - Fluxo Contínuo

ISSN Digital: 2316-381X

ISSN Impresso: 2316-3321

DOI: 10.17564/2316-381X.2020v8n2p398-412
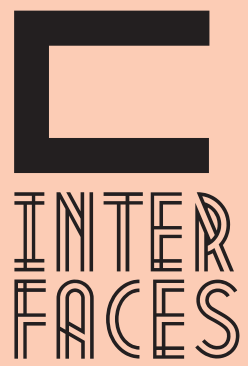

CIENTÍFICAS

\title{
CIDADES, VULNERABILIDADES E RISCOS: UMA ESTAGNAÇÃO NA GESTÃO DE RISCOS DA CIDADE DO NATAL/RN?'
}

CITIES, VULNERABILITIES AND RISKS: A STAGNATION IN RISK MANAGEMENT IN THE CITY OF NATAL/RN?

CIUDADES, VULNERABILIDADES Y RIESGOS: ¿UN ESTANCAMIENTOEN LA GESTIÓN DE RIESGOS EN LA CIUDAD DE NATAL/RN?

Rylanneive Leonardo Pontes Teixeira Zoraide Souza Pessoa ${ }^{3}$

10 presente artigo é fruto de resultados finais da monografia de graduação e da dissertação de mestrado do primeiro autor, intituladas respectivamente: "Vulnerabilidade socioambiental e desastres naturais: um estudo de caso da Defesa Civil Municipal de Natal" e "Planejamento urbano e adaptação climática: entre possibilidades e desafios nas cidades de Natal/RN e Curitiba/ PR”. A monografia foi defendida no Departamento de Políticas Públicas da Universidade Federal do Rio Grande do Norte (UFRN) em 2015, e a dissertação no Programa de Pós-Graduação em Estudos Urbanos e Regionais da mesma instituição em 2019.

\section{RESUMO}

0 nosso objetivo, com este artigo, é investigar como a cidade do Natal tem internalizado a gestão de riscos em sua agenda governamental local. Para tanto, seguimos as orientações de uma pesquisa com abordagem qualitativa, nos valendo de um conjunto de métodos: pesquisas bibliográfica e documental; estudo de caso, com aplicação de entrevistas semiestruturadas; observação de reuniões; e análise de conteúdo. Com a análise e discussão dos resultados, observamos que, mesmo com algumas políticas públicas ou ações direcionadas ao gerenciamento de riscos de desastres, a gestão municipal de Natal ainda não tem as questões ligadas ao meio ambiente como central em sua agenda governamental. Em síntese, concluímos que a gestão de riscos não se configura como temática prioritária das agendas pública e política da gestão municipal de Natal, sendo marginalizada por essas agendas em detrimento de outros temas que, por seu turno, são considerados mais importantes e relevantes pelos políticos e gestores municipais.

\section{PALAVRAS-CHAVE}

Agenda Governamental. Gestão de Riscos. Natal/ RN. Vulnerabilidade e Riscos. 


\section{ABSTRACT}

Our objective, with this paper, is to investigate how the city of Natal has internalized risk management in its local government agenda. For this, we follow the guidelines of a research with a qualitative approach, using a set of methods: bibliographic and documentary research; case study, using semi-structured interviews; observation of meetings; and content analysis. With the analysis and discussion of the results, we observed that, even with some public policies or actions directed to disaster risk management, the municipal management of Natal still does not have issues related to the environment as central to its governmental agenda. In summary, we conclude that risk management is not a priority theme in the public and political agendas of the municipal management of Natal, being marginalized by these agendas to the detriment of other themes that, in turn, are considered more important and relevant by politicians and municipal managers.

\section{KEYWORDS}

Government agenda. Risk management. Natal. Vulnerability and risks.

\section{RESUMEN}

Nuestro objetivo, con este artículo, es investigar como la ciudad de Natal ha internalizado la gestión de riesgos en su agenda de gobierno local. Por lo tanto, seguimos las pautas de una investigación con un enfoque cualitativo, utilizando un conjunto de métodos: investigaciones bibliográfica y documental; estudio de caso, utilizando entrevistas semiestructuradas; observación de reuniones; y análisis de contenido. Con el análisis y la discusión de los resultados, observamos que inclusive con algunas políticas públicas o acciones dirigidas a la gestión de riesgos de desastres, la gestión municipal de Natal aún no incorpora las cuestiones relacionadas con el medio ambiente como parte central de su agenda de gobierno. En resumen, concluimos que la gestión de riesgos no es un tema prioritario en las agendas públicas y políticas de la gestión municipal de Natal, siendo marginadas por esas agendas en detrimento de otros temas que, a su vez, se consideran más importantes y relevantes por los políticos y gerentes municipales.

\section{PALABRAS CLAVE}

Agenda del gobierno. Gestión de riscos. Natal. Vulnerabilidad y riesgos. 


\section{INTRODUÇ̄̃O}

No contexto de uma sociedade contemporânea caracterizada por constantes incertezas, ameaças e riscos, pensar sobre a gestão de riscos é de fundamental importância para compreender o que as cidades têm feito ou buscado fazer (ou não) para responder aos riscos de eventos adversos, como inundações e deslizamentos de terra. Para lidar com problemas e desafios como esses, as cidades precisam perceber e articular o que suas gestões municipais têm colocado em prática na perspectiva de evitar que tais eventos ocorram ou sejam intensificados.

No Brasil, a gestão de riscos ainda não consiste em uma pauta prioritária da agenda de governo federal sob o argumento que existem problemas muito mais preocupantes para serem solucionados (ALMEIDA; PASCOALINO, 2009). Esses autores comentam ainda que a gestão de riscos no país tem um caráter reativo, ou seja, é preocupada mais com a adoção de políticas públicas após a ocorrência de eventos adversos do que antes, com a antecipação dos problemas e suas possíveis alternativas. De modo geral, a falta de incorporação do tema da gestão de riscos ou de outras questões ligadas ao meio ambiente nas agendas governamentais vai além do contexto federal, ao passo que as agendas de governo estaduais e municipais também têm marginalizado e secundarizado essas pautas.

Especificamente na cidade do Natal, localizada no estado do Rio Grande do Norte/RN na região Nordeste do Brasil, também observamos fragilidades, lacunas e desafios quanto à incorporação da gestão de riscos na agenda governamental local. Diante disso, nos questionamos acerca dessa discussão a partir das seguintes indagações: em Natal, há um mapeamento das áreas de riscos e um plano ou uma política municipal de redução de riscos? Estão atualizados? 0 que a gestão municipal de Natal tem feito ou buscado fazer para gerir os riscos de eventos adversos da cidade?

É nessa perspectiva que temos o presente artigo, fruto de resultados finais da monografia de graduação e da dissertação de mestrado do primeiro autor, sob orientação do segundo autor. Ou seja, as análises e discussões aqui apresentadas foram iniciadas na monografia, se estendendo para a dissertação. Objetivamos, com este artigo, investigar como a cidade do Natal tem internalizado a gestão de riscos em sua agenda governamental local. Para tanto, seguimos as orientações de uma pesquisa com abordagem qualitativa, nos valendo de um conjunto de métodos que permitem o alcance dos resultados

Sob essa perspectiva, estruturamos este artigo, além desta introdução e das conclusões, em três seções. Na primeira, detalhamos os procedimentos metodológicos da pesquisa; na segunda, trazemos, do ponto de vista teórico-conceitual, a discussão sobre a questão ambiental e a gestão de riscos no contexto do Brasil; e na terceira e última, analisamos os resultados, discutindo-os na perspectiva da internalização do tema da gestão de riscos no âmbito da agenda governamental local.

\section{PROCEDIMENTOS METODOLÓGICOS DA PESQUISA}

A metodologia deste artigo está ancorada em uma pesquisa com abordagem de natureza qualitativa, sob a justificativa que a pesquisa desse tipo permite uma análise e discussão sobre os aspectos

Interfaces Científicas - Aracaju • V.8 - N.2 • p. 398 - 412 - 2020 - Fluxo Contínuo 
urbanos, sociais e ambientais em torno do que a gestão municipal de Natal, lócus deste estudo, tem feito ou buscado fazer (ou não) para enfrentar os riscos de eventos adversos no âmbito local.

Para isso, nos utilizamos de um conjunto de métodos de pesquisa. Inicialmente, realizamos uma discussão teórico-conceitual sobre questão ambiental e gestão de riscos no Brasil a partir da busca de produções científicas sobre o tema em plataformas como o Portal de Periódicos CAPES, de forma a subsidiar a revisão e atualização da literatura que compõe a discussão do próximo tópico.

A presente pesquisa é classificada como estudo de caso, uma vez que visamos incorporar aspectos e abordagens específicos da realidade de Natal à coleta e análise dos dados coletados, como bem pontua Yin (2010). Nesse sentido, nos valemos de pesquisas documental e de campo, bem como de observação de reuniões enquanto instrumentos de coleta dos dados.

Quanto à pesquisa documental, que compreendemos como procedimento que se utiliza da análise de documentos para compreensão e apreensão de um conjunto de dados (SÁ-SILVA; ALMEIDA; GUINDANI, 2009), analisamos três políticas públicas principais e importantes no contexto do gerenciamento de riscos, a saber: a Lei Complementar $n^{\circ} 082$, de 21 de junho de 2007, que regulamenta o plano diretor municipal em vigor; o Plano Municipal de Redução de Riscos (PMRR) de Natal, que define o mapeamento das áreas de riscos da cidade; e a Lei Complementar n 124, de 30 de junho de 2011, que estabelece a criação do Plano Diretor de Drenagem e Manejo de Águas Pluviais (PDDMA) da cidade.

Além da análise documental, acompanhamos as reuniões de revisão do plano diretor vigente da cidade, que iniciaram em 2018, se estendeu ao longo de 2019 e persiste no ano corrente. Visamos, com esse acompanhamento, observar como a gestão municipal de Natal vem inserindo as questões ligadas ao meio ambiente na agenda governamental local.

Paralelamente à pesquisa documental e à observação das reuniões do processo de revisão do plano diretor de Natal, realizamos pesquisa de campo, que se utiliza da aplicação de um roteiro de entrevistas semiestruturadas como principal instrumento de coleta dos dados (QUADRO 1). As entrevistas semiestruturadas são um roteiro com questões sobre a temática em análise (neste caso, gestão de riscos) que, todavia, possibilita que o entrevistado faça interferências a partir desse tema centra (GERHARDT et al., 2009).

Quadro 1 - Identificação dos entrevistados, instituições e datas de entrevistas

\begin{tabular}{|c|c|c|}
\hline Interlocutores institucionais & Instituição & Data de entrevista \\
\hline Interlocutor Institucional 1 & $\begin{array}{c}\text { Coordenadoria de Proteção e Defesa } \\
\text { Civil do Rio Grande do Norte }\end{array}$ & 18 de setembro de 2015 \\
\hline Interlocutor Institucional 2 & $\begin{array}{c}\text { Secretaria de Estado da Segurança } \\
\text { Pública e da Defesa Civil }\end{array}$ & 21 de setembro de 2015 \\
\hline Interlocutor Institucional 3 & $\begin{array}{c}\text { Secretaria Municipal da Defesa Civil } \\
\text { e Direitos Humanos de Natal }\end{array}$ & 22 de setembro de 2015 \\
\hline
\end{tabular}




\begin{tabular}{|c|c|c|}
\hline Interlocutores institucionais & Instituição & Data de entrevista \\
\hline Interlocutor Institucional 4 & $\begin{array}{c}\text { Departamento de Defesa Civil e } \\
\text { Ações Preventivas }\end{array}$ & 21 de agosto de 2017 \\
\hline Interlocutor Institucional 5 & $\begin{array}{c}\text { Secretaria Municipal de Meio Am- } \\
\text { biente e Urbanismo de Natal }\end{array}$ & 22 de agosto de 2017 \\
\hline Interlocutor Institucional 6 & $\begin{array}{c}\text { Secretaria Municipal de Segurança } \\
\text { Pública e Defesa Social de Natal }\end{array}$ & 22 de agosto de 2017 \\
\hline Interlocutor Institucional 7 & $\begin{array}{c}\text { Secretaria Municipal de Meio Am- } \\
\text { biente e Urbanismo de Natal }\end{array}$ & 12 de setembro de 2017 \\
\hline Interlocutor Institucional 8 & Conselho da Cidade do Natal & 19 de setembro de 2017 \\
\hline Interlocutor Institucional 9 & $\begin{array}{c}\text { Secretaria Municipal de Planejamen- } \\
\text { to, Orçamento e Finanças de Natal }\end{array}$ & 08 de fevereiro de 2018 \\
\hline Interlocutor Institucional 10 & $\begin{array}{c}\text { Coordenadoria Estadual de Proteção } \\
\text { e Defesa Civil do Rio Grande do Norte }\end{array}$ & 09 de maio de 2018 \\
\hline Interlocutor Institucional 11 & $\begin{array}{c}\text { Secretaria Municipal de Meio Am- } \\
\text { biente e Urbanismo de Natal }\end{array}$ & 14 de maio de 2018 \\
\hline
\end{tabular}

Fonte: Elaboração própria a partir de dados das pesquisas realizadas (2015; 2019).

Os dados aqui coletados são analisados a partir da técnica de análise de conteúdo (BARDIN, 2011), que é selecionada por ser uma técnica de ampla validação em pesquisas qualitativas (MOZZATO; GRZYBOVSKI, 2011). A análise de conteúdo dos dados coletados embasa as análises e discussões apresentadas nos dois tópicos a seguir: o de revisão teórico-conceitual e o de análise e discussão dos resultados.

\section{A QUESTÃO AMBIENTAL E A GESTÃO DE RISCOS NO CONTEXTO BRASILEIRO}

Na década de 1960, as questões ambientais começaram a ser percebidas como uma abrangente e importante problemática. Ferreira (2005, p. 29) comenta que a questão ambiental passou a ocupar "a agenda dos governos, organismos internacionais, movimentos sociais e setores empresariais em todo o mundo" a partir dessa década. Nesse período, autores como Hardin (1968) salientavam sobre a importância de resguardar o meio ambiente das atividades antrópicas, que buscavam satisfazer suas necessidades e seus desejos individuais sem pensar na sociedade como um todo. 
Foi devido a essa constante degradação ambiental que vários segmentos da sociedade começaram a se preocupar com as questões que envolvem o meio ambiente. Siqueira (2002) comenta que seria necessário, então, um desenvolvimento baseado na conservação do meio ambiente. Nesse sentido, surgiram vários eventos e documentos institucionais, como o documento "Nosso Futuro Comum", mais conhecido como "Relatório Brundtland"; e a Conferência das Nações Unidas para o Meio Ambiente (UNCED), também conhecida como "Rio-92".

Na perspectiva da elaboração e da implementação de políticas públicas, as questões ambientais no mundo dependem de um conjunto de atores sociais, que vão desde o Estado e seus governos, passando pela Academia e seus pesquisadores/cientistas, até a sociedade civil (SIQUEIRA, 2008). Esse autor assinala que o interesse desses segmentos sociais é que as políticas públicas ambientais sejam elaboradas e implementadas de modo a serem capazes de "possibilitar um gasto mais eficiente do dinheiro público, a satisfação da população com o desempenho dos agentes governamentais, a efetiva proteção ambiental, o desenvolvimento social e econômico sustentável” (SIQUEIRA, 2008, p. 426).

No Brasil, as políticas ambientais foram sendo desenvolvidas para responder às exigências impostas pelo movimento internacional ambientalista iniciado nos anos 1960 (PECCATIELLO, 2011). Antes mesmo desse período, nos anos 1950, já se verificava no território nacional a existência de iniciativas ligadas ao meio ambiente; porém, é só a partir dessa época, mais precisamente em meados da década de 1970, que se verifica uma maior notoriedade e representatividade por parte do movimento ambientalista brasileiro, com adoção de iniciativas na vertente ambiental (JACOBI, 2003).

É importante salientar, nessa ótica de abordagem sobre as questões ambientais no Brasil, que o Estado brasileiro tinha em meados de 1980 um "caráter desenvolvimentista e conservador" (ARAÚJO, 2000, p. 261), ou seja, não era voltado para o bem-estar da sociedade. Em comparação a essa época, vemos claramente um Estado brasileiro mais dedicado e alinhado às questões ambientais, ainda que com grandes fragilidades e lacunas. A Constituição Federal de 1988 surgiu como um instrumento que possibilita, pelo menos na teoria, o direito a um meio ambiente saudável e ecologicamente equilibrado, sendo de suma importância para uma sociedade mais sustentável (SALHEB et al., 2009).

Como assinalamos, o Estado brasileiro apresenta ainda hoje um conjunto de fragilidades e lacunas frente à incorporação da área ambiental no âmbito da agenda de políticas públicas, com baixa capacidade de enfrentar os problemas e desafios colocados nessa perspectiva. Ferreira (1998), nessa direção, enfatiza que a capacidade estatal brasileira tem perdido o papel de determinar rumos na dinâmica social, elaborando e implementando políticas públicas que visem responder a essas novas carências que estão em constante emergência. Enfim, as questões ambientais têm tido resistência de incorporação da agenda governamental (seja ela federal, estadual ou municipal), muito embora autores da teoria da modernização ecológica, como Mol e Sonnenfeld (2000), defendam que o Estado deveria assumir um papel mais proativo frente aos problemas ambientais.

No contexto dos debates ambientais, a discussão sobre o gerenciamento dos riscos de eventos adversos tem assumido ou deveria assumir lugar de destaque nas agendas governamentais, urbanas e ambientais das cidades brasileiras. Compreendemos aqui a gestão de riscos como um "processo que visa mitigar danos” (LITRE; BURSZTYN, 2015, p. 58), que leva em consideração quatro elementos essenciais:

(i) analisar o contexto de risco; (ii) avaliar o risco de acordo com esse contexto, por meio 
da identificação das ameaças, vulnerabilidades e consequências do impacto no sistema de produção familiar; (iii) identificar como os chefes de unidade produtiva e as instituições de extensão técnica, bancos, cooperativas etc., respondem aos riscos; e (iv) monitorar a evolução ao risco ao longo do tempo. (LITRE; BURSZTYN, 2015, p. 58).

Acreditamos que a gestão de riscos seja além de um processo mitigatório, se configurando, também, como um processo de adaptação na medida em que compreendemos a gestão de riscos como uma atividade que busca, além de reduzir impactos, evitar a ocorrência de eventos adversos, reduzindo vulnerabilidades e riscos socioambientais, como por exemplo, deslizamentos de terra e inundações.

Pensar sobre a gestão de riscos não tem como deixar de lado a discussão sobre planejamento urbano que, por sua vez, não pode ser simplesmente uma atividade de criar planos (COSTA; FERREIRA, 2010), de forma desvinculada das políticas públicas ou ações do Estado (VILLAÇA, 1999). Esse autor define o planejamento urbano como sendo "a ação do Estado sobre a organização do espaço intra-urbano" (VILLAÇA, 1999, p. 173). Zanirato e outros autores (2008) ponderam que a gestão de riscos, na interface com o planejamento urbano, reflete sobre as ações de prevenção que são tomadas sobre o "território do risco". Enfim, a gestão de riscos e o planejamento urbano são processos alinhados um ao outro e que se complementam.

No Brasil, o manual nacional de proteção e defesa civil e gestão de riscos, de 2017, é uma importante ferramenta de compreensão da gestão de riscos à nível nacional, cujo objetivo é evitar a exposição de populações do país a riscos de eventos adversos, buscando articular as ações de gestão de riscos com as de planejamento urbano (BRASIL, 2017). De acordo com esse documento, os planos diretores municipais e os planos municipais de redução de riscos ou mapeamento de áreas de riscos (duas das políticas públicas que são objeto de investigação no momento de análise e discussão dos resultados deste artigo) são alguns dos instrumentos de ordenamento territorial que incorporam a proteção e defesa civil, bem como a gestão de riscos no âmbito do planejamento urbano municipal.

No país, temos a Lei n ${ }^{0} 12.608$, de 10 de abril de 2012, que institui, por exemplo, a Política Nacional de Proteção e Defesa Civil (PNPDEC) e o Sistema Nacional de Proteção e Defesa Civil (SINPDEC). Dentre as determinações dessa Lei, está a que ampara a nova orientação da prevenção de desastres, estabelecendo como aspecto obrigatório para o planejamento ambiental de um ente municipal a identificação de áreas de risco (BRASIL, 2012).

Outra política pública direcionada ao gerenciamento de riscos de eventos adversos nas cidades brasileiras é o Plano Nacional de Gestão de Riscos e Resposta a Desastres Naturais (PNGRRDN), que trata-se de uma política do governo federal, aprovada no ano de 2012 e monitorada pela Casa Civil da Presidência da República, objetivando proteger a vida das pessoas, garantir a segurança delas, diminuir os danos resultantes de desastres e preservar o meio ambiente (BERTONE; MARINHO, 2013), por meio de ações divididas em quatro eixos, a saber: mapeamento, monitoramento e alertas, prevenção e resposta.

Diante do contexto apresentado, onde abordamos sobre a questão ambiental e a gestão de riscos no âmbito das agendas governamentais e urbanas do Brasil, pensar sobre a gestão de riscos, partindo de um estudo de caso, é de fundamental importância para uma melhor compreensão e apreensão do tema. É nesse sentido que apresentamos o próximo tópico. 


\section{A GESTÃO DE RISCOS NO CONTEXTO DA CIDADE DO NATAL}

No Brasil, a gestão de riscos não tem se configurado em tema prioritário da agenda de governo federal (ALMEIDA; PASCOALINO, 2009), tampouco das cidades brasileiras. Em Natal, lócus desta análise, constatamos que há um mapeamento das áreas de risco, o PMRR de Natal, que foi elaborado em 2008 pela Secretaria Municipal de Meio Ambiente e Urbanismo (SEMURB) em parceria com a Prefeitura Municipal (TEIXEIRA, 2019), com o objetivo de realizar:

O mapeamento das áreas para posteriormente traçar os rumos do planejamento urbano das mesmas, hierarquizadas por nível de criticidade, abrangendo os assentamentos localizados em encostas e/ou susceptíveis a inundações, localizados em flancos dunares e adjacências ou em outras áreas que se mostrem inadequadas para real e completa inserção social desses assentamentos na cidade formal. (NATAL, 2008, p. iii).

Esse mapeamento, todavia, se encontra em processo de atualização junto à revisão do plano diretor municipal em vigor, com contribuições do corpo técnico da gestão municipal, de pesquisadores das instituições de ensino e da sociedade civil da cidade ${ }^{3}$. 0 fato de a cidade apresentar um mapeamento das áreas de risco, ainda que desatualizado, nos leva a compreender que a cidade está levando em consideração as orientações do PNGRRDN, como apontamos anteriormente no momento de revisão da literatura.

Em 2015, passados aproximadamente sete anos da finalização do PMRR de Natal, o orçamento do Departamento de Defesa Civil e Ações Preventivas, para lidar com problemas e desafios nas áreas de defesa civil e gestão de riscos, era de $\mathrm{R} \$ 100.000,00$, “a ser destinada para estruturação e capacitação da Defesa Civil, em rubrica específica” (INTERLOCUTOR INSTITUCIONAL 3, 2015). Observamos, nessa direção, que a gestão de riscos, assim como outras temáticas ambientais continuam ainda não assumindo lugar central na agenda governamental de Natal, combinando com o que assinalam Teixeira, Pessoa e Di Giulio (2020a).

Nesse viés, pontuamos a necessidade de uma maior atuação por parte do Poder Público, por meio de suas instituições e seus atores, no que diz respeito à adoção de políticas públicas ou ações voltadas para o planejamento urbano que, para autores como Costa e Ferreira (2010), é um processo que não tem como ser dissociado da gestão de riscos na medida em que é uma atividade que pensa no futuro, utilizando-se das ações de gestão de riscos realizadas no presente. Para Zanirato e outros autores (2008), a gestão de riscos e o planejamento urbano são processos alinhados e complementares.

O Departamento de Defesa Civil e Ações Preventivas de Natal e a Universidade Federal do Rio Grande do Norte (UFRN), por meio do Grupo de Extensão e Pesquisa em Ergonomia (GREPE) e do Núcleo de Pesquisa sobre Desastres (NUPED), concluíram uma primeira versão (que ainda não foi

3 Informação coletada a partir dos dois autores deste artigo, que fizeram parte do processo de revisão do plano diretor vigente de Natal por meio da participação e colaboração com o subgrupo “Áreas de Risco" do Grupo de Trabalho de Áreas Especiais, conforme mencionado no momento dos procedimentos metodológicos. 
publicada) do Plano de Contingência (PLANCON) da cidade. Resultante de uma parceria técnico-científica, esse plano é voltado para o "enfrentamento de riscos e desastres de modo a reduzir os danos materiais e humanos que resultam da ocorrência desses desastres" (TEIXEIRA; PESSOA; DI GIULIO, 2020a, p. 106) na cidade.

Na cidade em análise, constatamos um sistema de alertas de desastres, que é fruto da Prefeitura Municipal com o Centro Nacional de Monitoramento e Alertas de Desastres (CEMADEN), do Ministério da Ciência, Tecnologia e Inovação (MCTI). Nesse aspecto, verificamos na cidade a existência de oito estações pluviométricas, que permitem acompanhar a quantidade de chuvas em todas as quatro regiões administrativas da cidade, onde, em casos de probabilidade de ocorrência de desastres, o Departamento de Defesa Civil e Ações Preventivas Natal é alertado para atuação. 0 representante entrevistado desse Departamento aponta:

[...] nós temos um sistema aqui de monitoramento... que nós temos oito pluviômetros automáticos espalhados pela cidade... que é um convênio com o CEMADEN, certo? E nós ficamos acompanhando a... a chuva em todas as regiões... nós espalhamos pluviômetros nas quatro regiões da nossa cidade e ficamos acompanhando a chuva (INTERLOCUTOR INSTITUCIONAL 4, 2017).

Nessa perspectiva do monitoramento e alertas, a cidade em questão apresenta ainda um radar meteorológico, instalado em 2013 na Base Aérea de Natal (BANT), em Parnamirim na Região Metropolitana de (RMN), visando ampliar a rede de observação das condições climáticas do RN e, assim, garantir um melhor acompanhamento das cidades do estado (TEIXEIRA, 2015; 2019). Saito (2018) comenta que os sistemas de alertas, como estações pluviométricas e radares meteorológicos, são ferramentas de redução de riscos de eventos adversos, como por exemplo, deslizamentos de terra e inundações.

A existência de instrumentos de monitoramento e alertas em Natal significa, de certo modo, o seguimento das orientações propostas pelo PNGRRDN, conforme assinalamos no tópico anterior. No entanto, percebemos ainda fragilidades e desafios a serem enfrentados pela gestão municipal de Natal, que poderiam ser enfrentados ou pelo menos atenuados ao passo que temas ligados ao meio ambiente, como é o caso da gestão de riscos de eventos adversos, fossem internalizados na agenda governamental local.

As ações de gestão de riscos também englobam as intervenções de drenagem urbana, que consistem em medidas estruturais adotadas pelo Estado, visando corrigir e/ou prevenir a ocorrência de eventos adversos (BRASIL, 2017). No caso de Natal, as ações de drenagem urbana são garantidas por meio do PDDMA da cidade, um dos instrumentos básicos do plano diretor municipal (NATAL, 2011). 0 Interlocutor Institucional 5 (2017) aponta que obras de drenagem urbana estão sendo realizadas na cidade e são essenciais para lidar com os riscos de eventos adversos. Sobre isso, o entrevistado pontua:

[...] Em Natal, tá sendo feito uma grande obra de saneamento, né? Mas o sistema de drenagem, como eu disse aqui no início, não acompanhou realmente o crescimento, então grande número de ocorrências nossas é de crateras que se abrem por causa de rompimento de tubulações, né? Então, existe um sistema precário que, se fosse feita essa grande 
obra minimizaria nossos, nossas áreas de risco... diminuiria muito nossas áreas de risco. (INTERLOCUTOR INSTITUCIONAL 5, 2017).

Por fim, constatamos ainda em Natal a existência de ações de enrocamento das praias, que se configuram como medidas "de revestimento com camadas ou blocos de pedra na linha da costa a fim de proteger o solo da erosão causada pelas ondas” (PAULA, 2015 apud TEIXEIRA; PESSOA; DI GIULIO, 2020b, no prelo).

Diante do que apresentamos, podemos constatar que, ainda que com algumas políticas públicas ou ações direcionadas ao gerenciamento de riscos de eventos adversos, a gestão municipal de Natal ainda não tem as questões ligadas ao meio ambiente como central em sua agenda governamental, como apresentamos a seguir nas conclusões a que chegamos com esta análise.

\section{CONCLUSÕES}

A gestão de riscos é ainda um desafio a ser enfrentado no âmbito da incorporação na agenda governamental, seja federal, estadual ou municipal; e isso se dá em virtude da falta de prioridade do tema nas pautas das agendas políticas e públicas. Outras temáticas ligadas diretamente ao meio ambiente, como as mudanças climáticas, também são pouco ou não são visadas nessas agendas, sendo, portanto, marginalizadas e secundarizadas.

No nível local, essas questões podem ser melhor visualizadas. Na cidade do Natal, por exemplo, observamos, a partir dos resultados da pesquisa, que a gestão municipal pouco tem avançado na direção da implementação e efetivação de uma rede de políticas públicas ou ações de gestão de riscos, muito embora conte com algumas iniciativas nessa perspectiva. Um exemplo disso é a existência do PMRR de Natal (mapeamento das áreas de risco da cidade) que, porém, não está atualizado, sem grandes avanços até o ano corrente, mesmo que fazendo parte das discussões e dos debates do atual processo de revisão do plano diretor vigente.

Em termos gerais, as políticas públicas ou ações realizadas pela gestão municipal de Natal são de caráter reativo, atuando sobre os eventos adversos após ocorrerem; e não proativo, quando se age sobre os riscos a fim de que não se tornem em desastres efetivos. Essa é uma realidade comum a outras cidades brasileiras.

Nessa ótica, alcançamos o objetivo proposto deste artigo, uma vez que conseguimos investigar como a cidade do Natal tem incorporado a gestão de riscos na agenda governamental local a partir da análise do que a gestão urbana de Natal tem feito ou buscado fazer ou deixado de fazer frente à gestão de riscos da cidade. Atrelado a isso, conseguimos responder também às questões indagadoras desta análise.

Este trabalho, além de buscar contribuir para a literatura nacional sobre a gestão de riscos no contexto de eventos adversos, pretende servir com os tomadores de decisão de políticas públicas que atuam frente ao tema, possibilitando-lhes a promoção de uma gestão mais efetiva e eficaz, a qual realize ações de mapeamento, monitoramento e alertas, prevenção e resposta, conforme estabelece o PNGRRDN. 


\section{REFERÊNCIAS}

ALMEIDA, L. Q. de; PASCOALINO, Aline. Gestão de risco, desenvolvimento e (meio) ambiente no Brasil - Um estudo de caso sobre os desastres naturais de Santa Catarina. XIII Simpósio Brasileiro de Geografia Física Aplicada. Viçosa, 2009.

ARAÚJO, Tânia Bacelar de. As políticas públicas no Brasil. In: Ensaios sobre desenvolvimento brasileiro: heranças e urgências. Rio de Janeiro: Revan Fase, 2000.

BARDIN, Lawrence. Análise de conteúdo. São Paulo: edições 70, 2011.

BERTONE, Pedro; MARINHO, Clarice. Gestão de riscos e resposta a desastres naturais: A visão do planejamento. 2013.

BRASIL. Ministério da Ciência, Tecnologia e Informação - MCTI. Governo lança Plano Nacional de Gestão de Riscos e Desastres Naturais. 2012. Disponível em: http://www.brasil.gov.br/ciencia-etecnologia/2012/08/assista-ao-lancamento-do-plano-de-gestao-de-riscos-e-desastres-naturais. Acesso em: 3 set. 2016.

BRASIL. Ministério da Integração Nacional - MI. Secretaria Nacional de Proteção e Defesa Civil. Departamento de Prevenção e Preparação. Módulo de formação: noções básicas em proteção e defesa civil e em gestão de riscos: livro base / Ministério da Integração Nacional, Secretaria Nacional de Proteção e Defesa Civil, Departamento de Minimização de Desastres. - Brasília: Ministério da Integração Nacional, 2017. Disponível em: file://G:/Mestrado\%20-\%20PPEUR/Dissertação/ Bibliografia\%20-\%20dissertação/Ordenamento\%20territorial\%20e\%20planejamento\%20 urbano/I\%20-\%20Gestao\%20de\%20Risco\%20-\%20Livro\%20Base.pdf. Acesso em: 5 jan. 2019.

COSTA, Everaldo Batista; FERREIRA, Tatiane Araújo. Planejamento urbano e gestão de riscos-vida e morte nas cidades brasileiras. OLAM-Ciência \& Tecnologia, v. 10, n. 2, 2010.

FERREIRA, Leila da Costa. A questão ambiental: sustentabilidade e políticas públicas no Brasil. São Paulo: Boitempo Editorial, 1998.

FERREIRA, Leila da Costa. A centralidade da interdisciplinaridade nos estudos sobre Ambiente e Sociedade. Revista Brasileira Multidisciplinar, v. 9, n. 2, p. 29-42, 2005.

HARDIN, Garrett. The tragedy of the commons. Science, v. 162, n. 3859, p. 1243-1248, 1968.

INTERLOCUTOR INSTITUCIONAL 1. Comunicação verbal. Coordenadoria de Proteção e Defesa Civil do Rio Grande do Norte. Entrevista realizada em: 18 de set. de 2015. 
INTERLOCUTOR INSTITUCIONAL 4. Comunicação Verbal. Departamento de Defesa Civil e Ações Preventivas. Entrevista realizada em: 21 de ago. de 2017.

INTERLOCUTOR INSTITUCIONAL 5. Comunicação Verbal. Secretaria Municipal de Meio Ambiente e Urbanismo de Natal. Entrevista realizada em: 22 de ago. de 2017.

GERHARDT, Tatiana Engel et al. Estrutura do projeto de pesquisa. In: GERHARDT, Tatiana Engel; SILVEIRA, Denise Tolfo (org.). Métodos de pesquisa. Porto Alegre: Editora da UFRGS, 2009.

JACOBI, P. Movimento ambientalista no Brasil. Representação social e complexidade da articulação de práticas coletivas. In: RIBEIRO, W. (org.). Publicado em Patrimônio Ambiental. São Paulo: EDUSP, 2003.

LITRE, Gabriela; BURSZTYN, Marcel. Percepções e adaptação aos riscos climáticos e socioeconómicos na pecuária familiar do bioma Pampa. Ambiente \& Sociedade, Campinas, v. 18, n. 3, p. 55-80, 2015.

MOL, Arthur P. J.; SONNENFELD, David A. Ecological modernization around the world: an introduction. Environmental Politics, v. 9, n. 1, p. 3-16, Spring 2000.

MOZZATO, Anelise Rebelato; GRZYBOVSKI, Denize. Análise de conteúdo como técnica de análise de dados qualitativos no campo da administração: potencial e desafios. Revista de Administração Contemporânea, v. 15, n. 4, p. 731-747, 2011.

NATAL. Lei Complementar n⿳0 082, de 21 de junho de 2007. Dispõe sobre o Plano Diretor de Natal e dá outras providências. 2007. file:///C:/Users/ponte/Downloads/24_Plano_Diretor\%20(2).pdf. Acesso em: 3 ago. 2018.

NATAL. Plano Municipal de Redução de Riscos do Município de Natal - Relatório Final. 2008. Disponível em: file:///C:/Users/ponte/Downloads/Vol_1_-_REL_AREAS_RISCO_-_Final\%20(3).pdf. Acesso em: 10 jan. 2019.

NATAL. Lei Complementar n⿳0 124, de 30 de junho de 2011. Dispõe sobre o Plano Diretor de Drenagem e Manejo de Águas Pluviais do Município de Natal e dá outras providências. Disponível em: https://leismunicipais.com.br/a/rn/n/natal/lei-complementar/2011/12/124/lei-complementarn-124-2011-dispoe-sobre-o-plano-diretor-de-drenagem-e-manejo-de-aguas-pluviais-do-municipiodo-natal-e-da-outras-providencias. Acesso em: 15 nov. 2019.

PECCATIELLO, Ana Flávia Oliveira. Políticas públicas ambientais no Brasil: da administração dos recursos naturais (1930) à criação do Sistema Nacional de Unidades de Conservação (2000). Desenvolvimento e Meio Ambiente, v. 24, 2011. 
PNUD - Programa das Nações Unidas para o Desenvolvimento. Reducing disaster risk: a challenge for development. New York, USA: UNDP, 2004. 129 p.

SAITO, Silvia Midori. Vulnerabilidades no contexto de sistemas de alerta de risco de desastres. Revista Gestão \& Sustentabilidade Ambiental, v. 7, p. 618-630, 2018.

SALHEB, Gleidson José Monteiro et al. Políticas públicas e meio ambiente: reflexões preliminares. Planeta Amazônia: Revista Internacional de Direito Ambiental e Políticas Públicas, n. 1, 2009.

SÁ-SILVA, Jackson Ronie; ALMEIDA, Cristovão Domingos de; GUINDANI, Joel Felipe. Pesquisa documental: pistas teóricas e metodológicas. Revista brasileira de histórica \& ciências sociais, $\mathrm{v}$. 1, n. 1, p. 1-15, 2009.

SIQUEIRA, Leandro de Castro. Produção de resíduos no restaurante universitário: diagnósticos para ações de Educação Ambiental no Programa Agenda 21 da Universidade de Brasília. 2002. 116 f. Dissertação (Mestrado em Ecologia) - Centro de Biociências, Universidade de Brasília, Brasília, 2002.

SIQUEIRA, Leandro de Castro. Política ambiental para quem? Ambiente \& Sociedade, Campinas v. XI, n. 2, p. 425-437, jul./dez. 2008.

TEIXEIRA, Rylanneive Leonardo Pontes. Vulnerabilidade socioambiental e desastres naturais: um estudo de caso da defesa civil municipal de Natal. 2015. 93 f. Monografia (Graduação em Gestão de Políticas Públicas) - Centro de Ciências Humanas, Letras e Artes. Universidade Federal do Rio Grande do Norte, Natal, 2015.

TEIXEIRA, Rylanneive Leonardo Pontes Teixeira. Planejamento urbano e adaptação climática: entre possibilidades e barreiras nas cidades de Natal/RN e Curitiba/PR. 2019. 187 f. Dissertação (Mestrado em Estudos Urbanos e Regionais) - Centro de Ciências Humanas, Letras e Artes. Universidade Federal do Rio Grande do Norte, Natal, 2019.

TEIXEIRA, Rylanneive Leonardo Pontes; PESSOA, Zoraide Souza; DI GIULIO, Gabriela Marques. Mudanças climáticas e capacidade adaptativa no contexto da cidade do Natal/RN, Brasil. Revista Geotemas, v. 10, n. 1, p. 95-115, 2020a.

TEIXEIRA, Rylanneive Leonardo Pontes; PESSOA, Zoraide Souza; DI GIULIO, Gabriela Marques. Cidades, mudanças climáticas e adaptação: um estudo de caso de Natal/RN, Brasil. 0 social em questão, Ano XXIII, n. 48, set./dez. 2020b. No prelo.

VILLAÇA, F. Uma contribuição para a história do planejamento urbano no Brasil. In: DEÁK, C.; SCHIFFER, S. R. (org.). 0 processo de urbanização no Brasil. São Paulo: Fupam; Edusp, 1999. p. 168-243. 
YIN, Robert K. Estudo de caso: planejamento e métodos / Robert K. Yin; trad. Daniel Grassi - 2.ed. Porto Alegre: Bookman, 2010.

ZANIRATO, S. H. et al. Sentidos do risco: interpretações teóricas. Revista Bibliográfica de Geografía y Ciencias Sociales, Barcelona, v. XIII, n. 785, p. 1-16, maio 2008 
2 Mestre e Doutorando em Estudos Urbanos e Regionais pela Universidade Federal do Rio Grande do Norte - UFRN; Graduado em Gestão de Políticas Públicas - UFRN. E-mail: pontesrylanneive@gmail.com, (84) 99488-1911.

3 Doutora em Ambiente e Sociedade pela Universidade Estadual de Campinas - UNICAMP; Mestra e Graduada em Ciências Sociais pela Universidade Federal do Rio Grande do Norte - UFRN; Professora Adjunta do Departamento de Políticas Públicas e do Programa de Pós-Graduação em Estudos Urbanos e Regionais - UFRN.

E-mail: zoraidesp@gmail.com

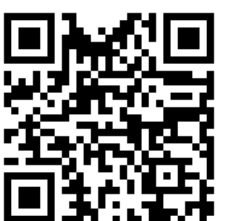

A autenticidade desse artigo pode ser conferida no site https://periodicos. set.edu.br

\section{(ㄷ) (1) (-)}

Este artigo é licenciado na modalidade acesso aberto sob a Atribuição-Compartilha Igual CC BY-SA

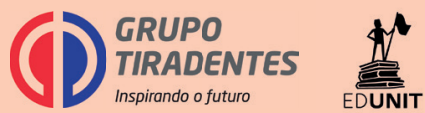

